\title{
Serum Magnesium Levels in Depression
}

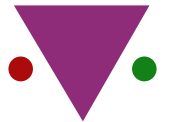

IJCRR

Section: Healthcare

Sci. Journal Impact

Factor: $6.1(2018)$

ICV: 90.90 (2018)

\section{Geeta Bhatia ${ }^{1}$, Anoushka Nair ${ }^{2}$, A. S. Chaudhari ${ }^{3}$, Sangeeta Trimbake ${ }^{4}$}

'Department of Biochemistry, MIMER Medical College, Talegaon Dabhade, Pune, India; ${ }^{2}$ MIMER Medical College, Talegaon Dabhade, Pune; ${ }^{3}$ Department of Biochemistry, MIMER Medical College, Talegaon Dabhade, Pune, lndia; ${ }^{4}$ Department of Biochemistry, MIMER Medical College, Talegaon Dabhade, Pune, India.

\section{ABSTRACT}

Background: Depression, a common mental disorder, has risen to be one of the leading causes of disability worldwide and a major cause of suicide attempts globally. There is evidence to suggest that magnesium affects the brain physiology and its role in NMDA (N-methyl-D-aspartate) receptor regulation makes it a factor of interest in depressive pathology.

Aim \& Objectives: To estimate the Serum Magnesium in newly diagnosed patients of depression and to compare it with the normal population value.

Methods: A cross-sectional study was conducted in the Department of Biochemistry and the Department of Psychiatry at MIMER Medical College, Bhausaheb Sardesai Talegaon Rural Hospital, Talegaon Dabhade, Pune patients were included. Their serum was collected before they started any medication, and was analysed for Magnesium level by xylitol blue method.

Results: The serum magnesium levels are found to be significantly lower than the normal range. The mean value of serum Magnesium in the study group was $1.72 \pm 0.33 \mathrm{mg} / \mathrm{dl}$, comparatively less than the population value of $2.1 \pm 0.26 \mathrm{mg} / \mathrm{dl}$

Conclusions: Serum Magnesium levels are decreased significantly in patients suffering from depression. Alteration of its level could play a role in the pathology of depression. There is a scope for use of magnesium level estimation to determine the level of depression and the efficacy of treatment. Use of Magnesium supplements in the treatment of depression may be effective and requires further research.

Key Words: Serum Magnesium (Mg), Depression, Hypomagnesemia, Role of NMDA

\section{INTRODUCTION}

According to WHO, Depression is a common mental disorder, characterized by sadness, loss of interest or pleasure, feelings of guilt or low self-worth, disturbed sleep or appetite, feelings of tiredness, and poor concentration. Depression affects more than 264 million people worldwide and is predicted to be the leading cause of disease burden by 2030 , based on disability-adjusted-life-year ${ }^{1,2}$

Magnesium is linked with brain biochemistry and fluidity of the neuronal membrane, making it one of the most essential minerals in the human body. ${ }^{3}$ It is a voltage dependant blocker for the N-methyl-D-aspartate (NMDA) receptors which are found on nerve cells. Some evidence suggests that alterations in magnesium regulate neurobiological pathways implicated in the pathophysiology of depressive illness. ${ }^{4}$ Even though the exact mechanism is yet to be known, hy- pomagnesemia has been suggested to affect neuronal regulation contributing to depression. ${ }^{5,6}$

According to various studies, ${ }^{7,8,9}$ magnesium supplementation has been linked to improvement in depressive symptoms, but the results are ambiguous and the consensus on the relationship between magnesium and depression has not been reached. Some studies have proposed that Magnesium may relieve depression by blocking the NMDA receptor, dysfunction of which is a causative factor in the pathology of depression. ${ }^{10}$

Review of literature suggests that studies on this topic have not been conducted in the Indian population in the recent past. With antidepressant trials of adequate dose and duration resulting in only about $50 \%$ of patients achieving remission ${ }^{11}$ and non-pharmacologic approaches requiring skilled professionals and several weeks to months to achieve

\section{Corresponding Author:}

Dr. Geeta Bhatia, Associate Professor, Department of Biochemistry, MIMER Medical College, Talegaon Dabhade, Pune, India. Phone: 09881253887; Email: geeta_bhatia0831@rediffmail.com

ISSN: 2231-2196 (Print)

Received: 23.07 .2020
ISSN: 0975-5241 (Online)

Revised: 21.09 .2020
Accepted: 19.10 .2020
Published: 24.11 .2020 
effectiveness, there is a great need for additional treatment options. Many studies have drawn up inconclusive reports, emphasizing the need for further research. ${ }^{12}$

Serum Magnesium acts as a good indicator of magnesium levels in the body and therefore its assessment can form the basis of the correlation between the level of magnesium and depression. A cross-sectional study of depressed patients with the normal range of serum magnesium as a reference will shed some light on the association of depression with serum magnesium levels.

\section{AIMS AND OBJECTIVES}

Aim: To estimate the levels of serum magnesium in clinically diagnosed patients suffering from depression.

Objective: To investigate the serum magnesium level in depressed patients and to compare it with the normal range.

\section{MATERIALS AND METHODS}

The study design used was a cross-sectional study. Blood samples of 37 clinically diagnosed patients of depression attending the OPD were collected and analyzed for levels of serum magnesium after obtaining approval from the Institutional Ethics Committee. The study was conducted at MIMER Medical College and Bhausaheb Sardesai Talegaon Rural Hospital, Department of Biochemistry and Psychiatry.

The normal value of serum $\mathrm{Mg}$ was taken as $2.1 \pm 0.26 \mathrm{mg} /$ dl.

Newly diagnosed cases that were not on medications and Magnesium supplements were included. Exclusion criteria were patients who were already under treatment for depression and patients suffering from complicated co-morbidities like bone abnormalities or under medications that affected magnesium level.

After informed consent from the patients, $2 \mathrm{ml}$ of venous blood was collected with all aseptic precautions. Serum was obtained and analyzed for estimation of magnesium level by the use of the Magnesium Colorimetric Assay kit which employs the Xylidyl blue method. ${ }^{13}$ A fully automated biochemical analyzer XL-640 was used.

Statistical analysis: SPSS Software. The data were expressed as mean \pm standard deviation. Mean values were compared with the normal range by the Mann Whitney test.

\section{RESULTS}

The study was conducted on 37 newly diagnosed patients of depression who were selected according to the inclusion and exclusion criteria. Table 1- shows the range of serum magnesium observed in 37 patients of depression.

The overall mean value of serum Magnesium in the study group is $\mathbf{1 . 7 2} \pm \mathbf{0 . 3 3} \mathbf{~ m g} / \mathbf{d l}$ which is comparatively lesser than the population value of $2.1 \pm 0.26 \mathrm{mg} / \mathrm{dl}$.

A Mann Whitney test indicated that the magnesium value of the study group was lower than the normal population value.

Figure 1 shows a diagrammatic representation of the distribution of serum magnesium levels in 37 depression patients. It is observed that serum magnesium levels in $70 \%$ of depression patients are below the normal range, $24 \%$ of depression patients are within the Normal range and $6 \%$ of depression patients are slightly above the normal range as compared to the reference normal range. Figure 2 shows the age-wise distribution of depression patients. The mean age of depression patients was $\mathbf{4 9 . 6} \pm \mathbf{1 9 . 4}$ years.

Table 2 illustrates serum magnesium levels in male and female depression patients. Out of 37 patients, 15 patients were males and 22 were females. Table 3 illustrates the mean serum $\mathrm{Mg}$ level in different age groups. It is observed that there is no markable change in serum $\mathrm{Mg}$ level in different age groups of depression patients.

The following observations were obtained on analysis:

The mean value of serum magnesium in cases is comparatively lesser than the reference normal range. It is also observed that no markable change in serum $\mathrm{Mg}$ level in different age groups and male \& female gender of depression patients.

\section{DISCUSSION}

Magnesium is known to play an important role in the physiological function of the brain and a variety of neuromuscular and psychiatric symptoms including various types of depression have been observed in magnesium deficiency. ${ }^{15}$

Our study revealed significant hypomagnesemia in the subjects compared to the normal population value, notably following previous research conducted on this topic by Afsaneh Rajizadeh et $\mathrm{al}^{14}$. The decrease in serum magnesium was not confounded by age or gender, though this could be attributed to small sample size.

The mechanism that has been proposed in many studies involves the voltage dependant blocking action that it has on NMDA receptors. A deficiency in Magnesium causes reduced blocking of the NMDA channels, thus creating a hyperexcitable state ${ }^{16}$ The blockade of NMDA receptors at rest has shown rapid antidepressant effects. ${ }^{17}$ The anti-depressant effect of Magnesium was also attributed to its effect on serotonergic, noradrenergic, and dopamine systems. ${ }^{18}$ 
A study conducted on mice that were given less magnesium in the diet than required displayed enhanced depression-like behaviour that was chronic antidepressant therapy sensitive. ${ }^{6}$

The results indicate an association between hypomagnesemia and depression which opens up the scope for use of Magnesium for monitoring the effect of treatment in depression. Hypomagnesemia and its relation to the intensity of depression have been studied. ${ }^{14}$ Increase in Magnesium levels with treatment has been noted. ${ }^{12}$ Erythrocyte magnesium is seen to normalize in parallel with clinical improvement. ${ }^{19}$ An inverse association between magnesium intake and depression scores has been proven in some studies ${ }^{20}$ Magnesium may also be used therapeutically. Its supplementation in the treatment of depression ${ }^{8,9,21}$ showed an ambiguity in their results thus necessitating the need for further research.

Limitations of the study should be noted. The sample size was small. Serum magnesium of the patients was assessed only once before the administration of medications. Subsequent changes in the magnesium levels were not analysed. Dietary intake was not taken into consideration. The relationship between hypomagnesemia and intensity of depression was not analysed.

\section{CONCLUSION}

The study conducted on the serum Magnesium levels in newly diagnosed patients of depression showed low levels of magnesium. The results corroborate with findings in previous studies. Alteration of magnesium levels in the body may play an important role in the development of depression, which can be attributed to its action on NMDA receptors. Evaluation of serum magnesium to monitor the level of depression and the efficacy of treatment needs to be researched upon. Magnesium intake may also have a therapeutic role in the treatment of depression, though further studies are required for the same.

\section{ACKNOWLEDGEMENT}

The authors wish to thank the staff of the Psychiatry department MIMER Medical College Dr. Aashish Ubale and Dr. Aneesh Bhat for their advice.

Authors acknowledge the immense help received from the scholars whose articles are cited and included in references to this manuscript. The authors are also grateful to authors/ editors/publishers of all those articles, journals, and books from where the literature for this article has been reviewed and discussed

\section{DECLARATIONS:}

Sources of Funding: No funding sources

\section{Conflict of Interest: None declared}

Ethical approval: The study was approved by the institutional ethics committee of MIMER Medical College Talegaon Dabhade.

\section{REFERENCES}

1. Spencer L James, Degu Abate, Kalkidan Hassen Abate, Solomon M Abay, Cristiana Abbafati et al. Global, regional, and national incidence, prevalence, and years lived with disability for 354 diseases and injuries for 195 countries and territories, 1990-2017: a systematic analysis for the Global Burden of Disease Study 2017. The Lancet. 2018; 392: 1789-1858.

2. Corinna Rahe, Bernhard T Baune, Michael Unrath, Volker Arolt, JürgenWellmann, Heike Wersching, Klaus Berger. Associations between depression subtypes, depression severity and diet quality: cross-sectional findings from the direct Study. BMC psychiatry. 2015; 15:38.

3. Serefko A, Szopa A, Wlaz P, Nowak G, Radziwon-Zaleska M, Skalski M, et al. Magnesium in depression. Pharmacol Reports. 2013;65(3):547-54.

4. Eby GA EbyKLMagnesium for treatment-resistant depression: a review and hypothesis. Med Hypotheses. 2010;74:649-60.

5. YingyingGu, Kai Zhao, Xiaoqian Luan, Zhihua Liu, Yan Cai, Qiongzhang Wang, Beilein Zhu, Jicai He. Association between serum magnesium levels and depression in stroke patients. Aging Dis. 2016 Dec; 7(6): 687-690.

6. Nigel Whittle, Lin Li, Wei-Qiang Chen, Jae-Won Yang, Simone B. Sartori, GertLubec, Nicolas Singewald. Changes in brain protein expression are linked to magnesium restriction-induced depression-like behaviour. 2011; 40(4): 1231-1248.

7. Al-Dujaili AH, Al-Hakeim HK, Twayej AJ, Maes M. Total and ionized calcium and magnesium are significantly lowered in drug-naïve depressed patients: effects of antidepressants and associations with immune activation. Metab Brain Dis. 2019;34(5):1493-1503.

8. Marie-Laure Derom, Miguel AÁ. Martínez-González, Maria del CarmenSayón-Orea, Maira Bes-Rastrollo, Juan J. Beunza, Almudena Sánchez-Villegas. Magnesium Intake Is Not Related to Depression Risk in SpanishUniversity Graduates. J Nutr. 2012 April; 142(6): 1053-1059.

9. Trevino K, McClintock SM, McDonald Fischer N, Vora A, Husain MM. Defining treatment-resistant depression: a comprehensive review of the literature. Ann Clin Psych. 2014; 26(3):222-32.

10. Emily K. Tarleton and Benjamin Littenberg. Magnesium Intake and Depression in Adults. J Am Board Fam Med. 2015; 28(2): 249-256.

11. Rajizadeh A, Mozaffari-Khosravi H, Yassini-Ardakani M, Dehghani A. Effect of magnesium supplementation on depression status in depressed patients with magnesium deficiency: A randomized, double-blind, placebo-controlled trial. Nutrition. 2017; 35:56-60.

12. Giovanni Camardese, Luisa De Risio, GiusyPizi, BrunaMattioli, Francesco Buccelletti, Riccardo Serrani, Beniamino Leone, Alessandro Sgambato, Pietro Bria \& Luigi Janiri. Plasma magnesium levels and treatment outcome in depressed patients. Nutritional Neuroscience. 2012; 15:2,78-84.

13. V.Chromý, V.Svoboda, I.Štěpánová. Spectrophotometric determination of magnesium in biological fluids with xylitol blue II. Elsevier. 1973; 7(2): 208-217. 
14. AfsanehRajizadeh, Hassan Mozaffari-Khosravi, MojtabaYassini-Ardakani, Ali Dehghani. Serum Magnesium Status in Patients Subjects with Depression in the City of Yazd in Iran 2013-2014. Biol Trace Elem Res. 2016; 171(2): 275-282.

15. W. Cheungpasitporn, C. Thongprayoon, M. A. Mao, N. Srivali, P.Ungprasert, N. Varothai, A. Sanguankeo, W. Kittanamongkolchai, S. B. Erickson. Hypomagnesaemia linked to depression: a systematic review andmeta-analysis. Internal Medicine Journal. 2015; 45(4): 436-440.

16. Pittenger C, Sanacora G, Krystal JH. The NMDA receptor as a therapeutic target in major depressive disorder. CNS Neurol Disord Drug Targets. 2007 April; 6(2):101-15.

17. Autry AE, Adachi M, Nosyreva E, et al. NMDA receptor blockade at rest triggers rapid behavioural antidepressant responses. Nature. 2011;475(7354):91-95.

18. Cardoso CC, Lobato KR, Binfaré RW, et al. Evidence for the involvement of the monoaminergic system in the antidepressant-

Table 1: Range of Serum Magnesium Observed in 37 Depression Patients

\begin{tabular}{lc} 
Serum Magnesium level & Number of patients \\
\hline Below $1.84 \mathrm{mg} / \mathrm{dl}$ & 26 \\
$1.84-2.36 \mathrm{mg} / \mathrm{dl}$ & 9 \\
Above $2.36 \mathrm{mg} / \mathrm{dl}$ & 2 \\
\hline
\end{tabular}

Table 2: Mean Sr. Magnesium in Males and Females

$\begin{array}{ccc}\text { GENDER } & \begin{array}{c}\text { MALES } \\ (\mathrm{n}=15)\end{array} & \text { FEMALES } \\ (\mathrm{n}=22)\end{array}$

Sr. Mg value (mg/dL)

1.73

1.72

Table 3: Mean Serum Magnesium Values in Different Age Groups

\begin{tabular}{lcc} 
Age & No. of Patients & $\begin{array}{c}\text { Mean S. Mg level in } \\
\mathrm{mg} / \mathrm{dl}\end{array}$ \\
$<20$ & 2 & 1.74 \\
$20-40$ & 12 & 1.70 \\
$40-60$ & 5 & 1.72 \\
$>60$ & 17 & 1.74 \\
\hline
\end{tabular}

like effect of magnesium. Prog Neuropsychopharmacol Biol Psychiatry. 2009; 33(2):235-242.

19. Widmer J, Bovier P, Karege F, et al. Evolution of blood magnesium, sodium and potassium in depressed patients followed for three months. Neuropsychobiology. 1992; 26(4):173-179.

20. Felice N. Jacka, Simon Overland, Robert Stewart. Association Between Magnesium Intake and Depression and Anxiety in Community-Dwelling Adults: The Hordaland Health Study. Sage journals. 2009; 43 (1): 45-52

21. Ryszewska-Pokraśniewicz B, Mach A, Skalski M, et al. Effects of Magnesium Supplementation on Unipolar Depression: A Placebo-Controlled Study and Review of the Importance of Dosing and Magnesium Status in the Therapeutic Response. Nutrients. 2018;10(8):1014.

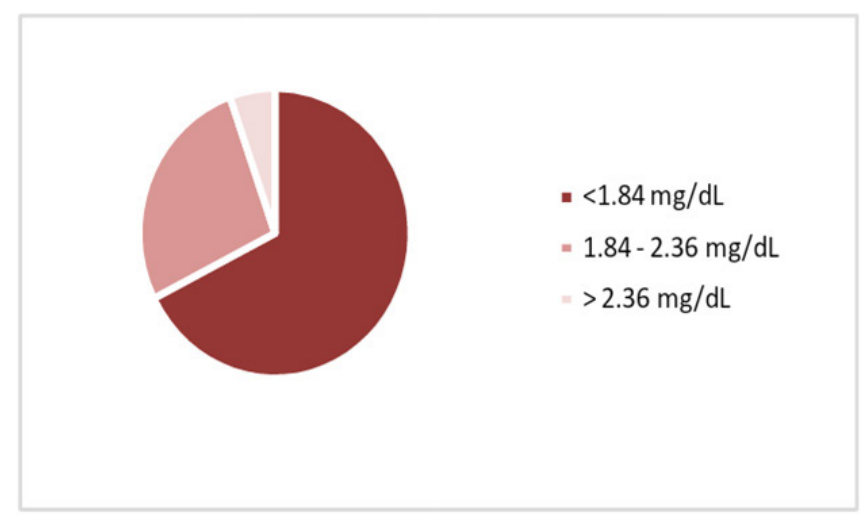

Figure 1: Serum Magnesium Levels In 37 Patients.

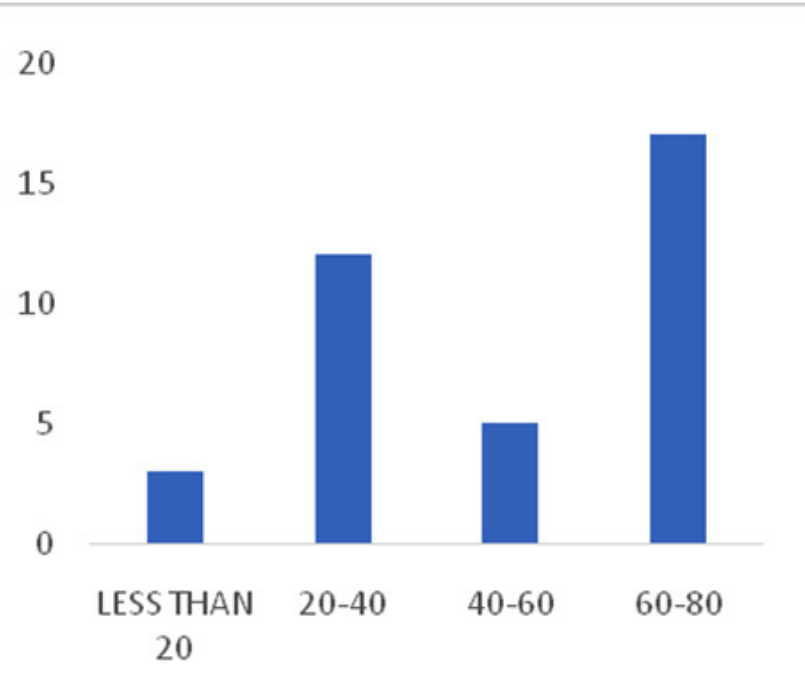

Figure 2: Age Distribution. 